\title{
Hemo Valve Device
}

National Cancer Institute

\section{Source}

National Cancer Institute. Hemo Valve Device. NCI Thesaurus. Code C50335.

A device component of a catheter assembly designed to prevent backflow of blood and thus minimize inadvertent blood loss while accessing the vasculature. 